\title{
AIRPORT SURFACE GRIDLOCK ANALYSIS: A CASE STUDY OF CHICAGO O'HARE 2007
}

\author{
Saba Neyshabouri ${ }^{1}$, Lance Sherry ${ }^{2}$, Karla Hoffman ${ }^{3}$ \\ Center for Air Transportation Systems Research (CATSR), George Mason University, Fairfax, VA
}

\begin{abstract}
The evolution of Air Traffic Control (ATC) and Traffic Flow Management (TFM) over the last decade has resulted in improved coordination of departures and enroute trajectories to minimize airborne congestion and airborne holding. Since the system is a "closed-system," the effect of these changes has been to shift airborne holding, to holding flights on the airport surface at the origin. This has placed increased emphasis on the coordination of gates, remote stands, airport parking, and surface trajectories. Previous research in this area has evaluated surface operations at specific airports through manual observation and/or surface track data, and through aggregate airport data and air traffic control logs.
\end{abstract}

The purpose of this research is to develop a tool to systematically measure airport surface gridlock using publicly available data over extended periods of time (e.g. one year). The tool uses ASPM and AOTP data to count the number of aircraft on the surface but not at the gates $\left(\mathrm{m}_{\mathrm{i}}\right)$. A measure of surface gridlock for a day is determined by identifying the number of flights on the surface (but not at the gates) for each 15-minute period in a 24 hour day. The maximum, mean, and median 15 minute flight count for a day is used to characterize the airport performance for a 24 hour period.

A case study analysis of flight operations at Chicago O'Hare airport in 2007 identified the number of flights on the surface (but not at a gate) for each 15-minute period. ORD experienced an average in maximum 15-minute surface flight count of 97 flights with a standard deviation of 18 flights. Twenty-four days in the year experienced a maximum surface flight count in excess of 1.5 times the standard deviation ( $\approx 125$ flights $)$. Fifteen days in the year experienced a maximum surface flight count in excess of 2 times the standard deviation $(\approx 134$ flights). Eight days in the year experienced a maximum surface flight count in excess of 3 times the standard deviation ( $\approx 150$ flights). The maximum surface flight count in excess of twice the standard deviation is concentrated in the summer convective season, and the winter snow season.

Detailed analysis of the operations when the maximum surface flight count was in excess of three times the standard deviation identifies irregular operations with significant reductions in operations due to cancellations. However the coordination between arrivals, gates, and departures results in surface congestion.

These results suggest that modernization initiatives that address normal operations are unlikely to affect these irregular operations.

\section{Introduction}

The Air Transportation System (ATS) in United States has major economic impact on the country's Gross Domestic Product (GDP) .The ATS is a largescale network that operates over 50000 flights on a daily basis [1]. Disruptions and inefficiencies in the system can cause delays that have ripple effects due to the networked structure of the system. The cost of delays in ATS in 2007 was estimated to be more than 27 billion dollars in direct costs. It is estimated that these delays, reduced the GDP by 4 billion dollars [2]. To put these numbers in perspective, the net operating revenue from all the operating airlines in 2007 was reported to be, approximately 7.7 billion dollars [3].

The evolution of Air Traffic Control (ATC) and Traffic Flow Management (TFM) over the last decade has resulted in improved coordination of departures and enroute trajectories to minimize

\footnotetext{
${ }^{1}$ Ph.D. student in Systems Engineering and Operations research department, sneyshab@masonlive.gmu.edu

${ }^{2}$ Associate Professor Systems Engineering and Operations Research (SEOR) and Director Center for Air Transportation Systems Research (CATSR) lsherry@gmu.edu

${ }^{3}$ Professor, Systems Engineering \& Operations Research, khoffman@ gmu.edu
} 
airborne congestion and airborne holding. Since the system is a "closed-system," the effect of these changes has been to shift airborne holding to holding flights on the airport surface at their origin until an arrival slot is available at their destination. This has placed increased emphasis on the coordination of gates, remote stands, airport parking, and surface trajectories.

Research on Air Traffic Flow Management, tends to focus runway capacity as the only constraining factor at the airports (see [4]-[6])]. This consideration ignores the holding capacity of the airport and can generate solutions for optimal traffic flow that are feasible yet result in congestion at the airport.

This paper describes a methodology for determining the number of flights on the airport surface but not a gate. A case-study analysis of Chicago-O'Hare airport for 2007 was conducted. The results of this study:

- ORD experienced an average maximum 15minute surface flight count of 97 flights with a standard deviation of 18 flights.

- Twenty-four days in the year experienced a maximum surface flight count in excess of 1.5 times the standard deviation ( $\approx 125$ flights $)$.

- Fifteen days in the year experienced a maximum surface flight count in excess of 2 times the standard deviation ( $\approx 134$ flights).

- Eight days in the year experienced a maximum surface flight count in excess of 3 times the standard deviation ( $\approx 150$ flights).

This fat-tailed phenomenon suggests a phase change in operations that results in these rare but irregular operations. This suggests that modernization initiatives that address normal operations are unlikely to affect these irregular operations. Further, detailed analysis of these operations is required to better understand how to predict their occurrence and steps to address them.

\section{Previous Research}

An internal report by Metron Aviation [7] examined the issue of grid-lock at airports for the years of 2004 and parts of 2005. Multiple reasons for this phenomenon were identified through interviews with traffic controllers/managers and searches of Traffic Control Logs for the term "grid-lock." One hundred and ninety two (192) incidents on 125 distinct days at 32 different airports were identified.

This report used a Surface Count metric - total number of flights on the surface of the airport including gates - for analysis. ETMS DZ (departure) and AZ (arrival) messages were used as a data source. This approach assumes the number of flights on the surface at the beginning of the day is zero. Due to this assumption, the Surface Count metric can take on negative values for the count on the surface. Analysis showed that surface counts and grid-lock incidents are related.

Stroiney and Levy [8] demonstrate the benefits of a departure queue management system to transfer as much taxi-delay possible to a cheaper delay (gate delays). This is achieved by managing the length of the departure queue. Taxi delays are absorbed at the gates or in areas in which flights can park and wait with their engines off.

This study simulated the departure queue management system for JFK airport and estimated an annual savings of $\$ 57 \mathrm{M}$. A summary of savings in taxi times per day, from implementing such system across 22 US airports is presented. The effect of limited gate capacity is discussed. The interdependence between arrivals and departures are not considered.

A detailed study on the effects of controlled departure rates at Boston Logan International Airport (BOS) is covered in [9]. A methodology for estimating the departure rate as a function of arrival demand is presented. Departure rate estimation is done for specific configuration at BOS. The effects of other parameters, on estimation such as fleet mix, are considered.

This paper defines an Airport Saturation Point as the threshold for the number of flights on the surface waiting to depart, beyond which the departure rate will not increase. The methodology includes solving a number of optimization problems to estimate the parameters, based on historical data. In addition, the results are very specific to the airport and configuration. Effects of limited gate capacity are not considered. 


\section{Methodology}

This section describes the data sources and algorithms used to determine the count of flights on the airport surface but not at the gates.

\section{Data Sources}

The methodology can use either AOTP or ASPM data to perform the analysis. ASPM is preferred as it includes all the operations. Therefore the results and approximations for surface congestion are closer to reality.

- Airline On-Time Performance (AOTP) :Includes all the domestic operating airlines with more than $1 \%$ traffic

- Aviation System Performance Metrics (ASPM) :Includes all the operations; international, domestic, General Aviation (GA)

ASPM data is more comprehensive in terms of instances, therefore it is expected that the results obtained by using ASPM data will exhibit higher values than those calculated using AOTP data.

\section{Algorithm}

To be able to identify grid-lock due to congestion on the surface of the airport, the following methodology was developed to quantify the number of flights on the surface of the airport at any given time.

To count the number of flights on the surface at any given time of the day, each day is divided into discrete time windows of 15 minutes duration. In this paper, each time window is assumed to be, 15 minutes long, therefore, each day has 96 intervals called Time Windows (TW). A 97th interval is included to capture the flights arriving after midnight. Over-night flights are those, which parts of their operations has been extended to the beginning of the next day. For example, a flight that was scheduled to arrive at ORD before midnight, but it is delayed so it arrives after midnight is assumed to arrive in the $97^{\text {th }}$ time interval. This is done so the count all the flights in a day can be accounted for.

Delays that are 15 minutes or longer are considered in the delay calculations while early arrivals/departures (negative delays) are considered to have zero delays.
Scheduled departures/arrivals are mapped to their associated time interval of the day using the following formula:

$$
T W_{f}=\left\lfloor\left(4 \times \text { Hour }_{f}\right)+\frac{\text { Minute }_{f}}{15}\right\rfloor+1
$$

This formula is consistent with the format used in other data sources such as ASPM and AOTP .

In the case of using AOTP data, cancelled and diverted flights are excluded from the counts.

The number of scheduled and actual operations of each type (Arrival/Departure and Wheel On/Off) are calculated and mapped to each time window of the day.

Assigned delays are calculated as well as the cumulative delays. Knowing the actual count of arrivals (landings and arrival to the gate) and departures (take-offs and gate push-backs) can provide us with statistics required to count the number of flights at each time. To count the number of flights on the surface of the airport, all the arrival flights from the moment of landing (Wheels on) and until the time of take-off (Wheels off) in case of departure flights must be counted.

It is important to note that scheduled and actual arrival/departure times are the arrival/push-back times to/from the gate. Flights can still be on the surface after they have pushed back from the gate (case of departures) or they can be waiting for an available gate after they have landed (in the case of arrivals). These flights should be counted to consider the flights on the surface and in fact can cause congestion in taxiways and grid-lock.

In [7] a similar methodology is proposed which provides a biased estimate of the congestion (S) that assumes that in the beginning of the day, there are no flights on the surface and the count of flights on the surface at each given time is equal to:

$$
S_{t}=C R A_{t}-C R D_{t}
$$

In the above equation $C R A_{t}$, is the Cumulative Runway Arrivals (landings) up to time $t$, while $C R D_{t}$ is the Cumulative Runway Departure (takeoffs) up to time $t$. This provides a biased estimate for the surface count since it does not take into account the initial count of flights at the beginning of the time 
horizon. This can lead to negative surface counts in cases when more departures are operated than arrivals. This case actually happens at airports in which many flights push back from the gates early in the morning such as in PHL and LGA.

Also not having the initial count of flights may adjust the results significantly. Having a net amount of 100 flights on the surface of an airport with the initial count of zero might not pose a great threat of grid-lock, while having 300 flights sitting at the airport at the beginning of the day and then adding an additional 100 flights may pushes the airport well beyond its carrying capacity.

A methodology based on matching flight tail numbers, for estimating the count of flights on the surface of the airport at the beginning of the day is proposed. It is assumed that at the beginning of the day all flights are at the gates. It is observed that in hub airports, flights perform several round-trips from and back to the airport. Therefore in a specific day, a tail number can be observed in both arrival and departure flights multiple times. The following algorithm tries to find the earliest operation (arrival or departure) performed by a tail number:

- Initial Count $=0$

- $\quad$ For each DepTail\# in Departures

\section{- $\quad$ Find all matching Tail\# with DepTail\# in the same list \\ - Find the earliest scheduled departure assigned to that Tail\# \\ - $\quad$ For each Tail\# in Arrivals \\ - $\quad$ Find all matching Tail\# with DepTail\# \\ - $\quad$ Find earliest scheduled arrival assigned to that Tail\# \\ - If Earliest Assigned DepTime< Earliest Assigned ArrTime for that Tail\#}

- Initial Count= Initial Count +1

As it was mentioned before, to have the actual count of the flights on the surface of the airport (including: ramp, taxiways, gates etc.), ON/OFF times should be used in calculations. However, employing the gate arrival/departure times in the calculations can help us have a better understanding of the system.

To calculate the total Surface Count (SC) at each time, following parameters are required:

- $\mathrm{A}_{\mathrm{t}}$ : Cumulative count if arrival flights to the airport (Land) up to time t.

- $\mathrm{D}_{\mathrm{t}}$ : Cumulative count of departures (Take-off) up to time $\mathrm{t}$.

- IC: Initial count of flights on the surface of the airport at the beginning of the day.

Considering the above mentioned definitions, the following formulas can be used to calculate a more accurate estimate of count of the flights on the surface of an airport:

$$
\begin{aligned}
& S C_{t}=S C_{t-1}+a_{t}-d_{t} ; \quad S C_{0}=I C \\
& \text { Or, } \\
& S C_{t}=I C+A_{t}-D_{t}
\end{aligned}
$$

In which $a_{t}$ and $d_{t}$ are the number of arrivals and departures operated during time $\mathrm{t}$ (not cumulative count). While $A_{t}$ and $D_{t}$ are cumulative operations (arrivals and departures respectively) performed up to time t. Using gate arrivals and departures will not provide us with the correct count of flights on the surface, since flights can spend long time waiting in a taxi queue to either take off or arrive at the gate. However, using gate operations times can provide us with deeper insights to the problem.

If the surface count using gate times instead of wheel times is calculated, the number of flights sitting at the gates at each time is provided (GC). Using wheel times will provide the total number of flights on the surface (gates+ taxiways+ ramps+ etc.). There exists an important relationship between gate count (GC) and surface count (SC) which makes the GC attractive for our study:

$$
G C_{t}=\lim _{\text {TaxiTimes } \rightarrow 0} S C_{t}
$$

The above formulation means that, if the time used to taxi flights to and from the gates would approach to zero, the number of flights on the surface would be equal to the count of flights at the gates. Intuitively, SC would be equal to GC if flights could take off from the gates or land directly at the gate. 
Gate count is important since it provides a baseline for comparisons, as well as information about how busy the gates are. The difference between $\mathrm{SC}$ and $\mathrm{GC}$ at each time provides the number of flights being taxied to/from the gates. Having a very large number for this parameter $\left(\mathrm{SC}_{\mathrm{t}}-\mathrm{GC}_{\mathrm{t}}\right)$ can be used as an indicator for grid-lock. The rationale is that the surface of the airport is a capacitated (limited) resource and only a finite number of flights can actually move around without any interruptions in their smooth operations. The capacity of an airport is a function of its size, configuration of its terminals, construction and operations, which can be determined by an expert.

If the number of moving (or total) flights on the surface exceeds its limit, it can cause interruptions in the operations, which is called grid-lock. For each day, the maximum (M), mean and median of the difference between SC and GC is calculated. In the next section, a computational study is done to perform the analysis presented above.

\section{Case Study Chicago O'hare 2007}

Statistics for flights for each month in 2007 is shown in Table 1 . The monthly departures from ORD range from 40800 to 49007 . The monthly arrivals to ORD range from 40900 to 49010 . Departure taxi Time is more than 11 million minutes Arrival Taxi Time is only $46 \%$ of departure taxi time. A total of 557341 departures as well as 557938 arrivals were performed in 2007. More than 10.9 million of departure delay in minutes and greater than 11.9 million of arrival delay in minutes were generated into the system. Greater than 11 million departure taxi times were recorded while the arrival taxi times were added up to more than 5 million minutes.

The statistics for the $m_{i}$ for each day at ORD in 2007 are summarized in Table 2. This table shows the min, max, median, and mean for functions of $\mathrm{m}_{\mathrm{i}}$.

\begin{tabular}{|l|rrr|}
\cline { 2 - 4 } \multicolumn{1}{c|}{} & Max(mi) & Avg(mi) & Med(mi) \\
\hline Average & 97.16 & 49.94 & 57.6 \\
Min & 61 & 27 & 30 \\
Max & 188 & 113 & 125 \\
Std Dev & 18.24 & 11.65 & 12.33 \\
\hline
\end{tabular}

Table 2 -Ranges for functions of surface count

Usually the distribution for each day is righttailed. It can be seen that the standard deviation for the maximum surface congestion is greater than the average or median surface congestion throughout the year.

Note that that this analysis breaks each day into 96+1 time intervals and calculates various statistics that are mentioned above, which cannot be presented here in detail.

The value $\mathrm{M}$ (Maximum difference between SC and GC throughout the day) for each day is calculated. In 2007, M, averages approximately 97 flights moving on the surface with the standard deviation of approximately 18 flights. Figure 1 presents the distribution for the values of $M$ and average and median of the surface (not gate) count.

Values for M range between 60 to nearly 190 at ORD during 2007. While most of the time the greatest number of flights on the surface (but not at the gates) lies between 80 to 115 , there are extreme

\begin{tabular}{|c|cccc|cccc|}
\hline ORD & $\begin{array}{c}\text { Departure } \\
\text { Count }\end{array}$ & $\begin{array}{c}\text { Delay } \\
\text { Min }\end{array}$ & $\begin{array}{c}\text { Delay } \\
\text { TW }\end{array}$ & $\begin{array}{c}\text { DepTaxi } \\
\text { Min }\end{array}$ & $\begin{array}{c}\text { Arrival } \\
\text { Count }\end{array}$ & $\begin{array}{c}\text { Delay } \\
\text { Min }\end{array}$ & $\begin{array}{c}\text { Delay } \\
\text { TW }\end{array}$ & $\begin{array}{c}\text { ArrTaxi } \\
\text { Min }\end{array}$ \\
\hline Jan & 47470 & 984220 & 106276 & 953495 & 47674 & 1115263 & 114875 & 474695 \\
Feb & 40861 & 1130577 & 108407 & 848275 & 40942 & 1133763 & 109211 & 460697 \\
Mar & 47717 & 1112397 & 114622 & 968206 & 47703 & 1339406 & 129401 & 428142 \\
Apr & 46232 & 919325 & 101336 & 908628 & 46205 & 1083985 & 112124 & 402835 \\
May & 49007 & 612461 & 85112 & 959165 & 49010 & 685841 & 89805 & 421170 \\
Jun & 46655 & 977167 & 105301 & 995435 & 46674 & 1098032 & 113429 & 421281 \\
Jul & 48300 & 878272 & 100781 & 965572 & 48326 & 927258 & 104268 & 445706 \\
Aug & 48393 & 1052452 & 111349 & 1049485 & 48458 & 1092251 & 114263 & 467015 \\
Sep & 46048 & 574535 & 80064 & 912144 & 46189 & 592429 & 81438 & 423555 \\
Oct & 48179 & 631301 & 85412 & 966298 & 48389 & 671798 & 88288 & 427680 \\
Nov & 45651 & 659483 & 84584 & 850409 & 45698 & 683115 & 86348 & 401820 \\
Dec & 42828 & 1417239 & 128333 & 945526 & 42700 & 1521641 & 135234 & 457243 \\
\hline Sum & 557341 & 10949429 & 1211577 & 11322638 & 557968 & 11944782 & 1278684 & 5231839 \\
\hline
\end{tabular}




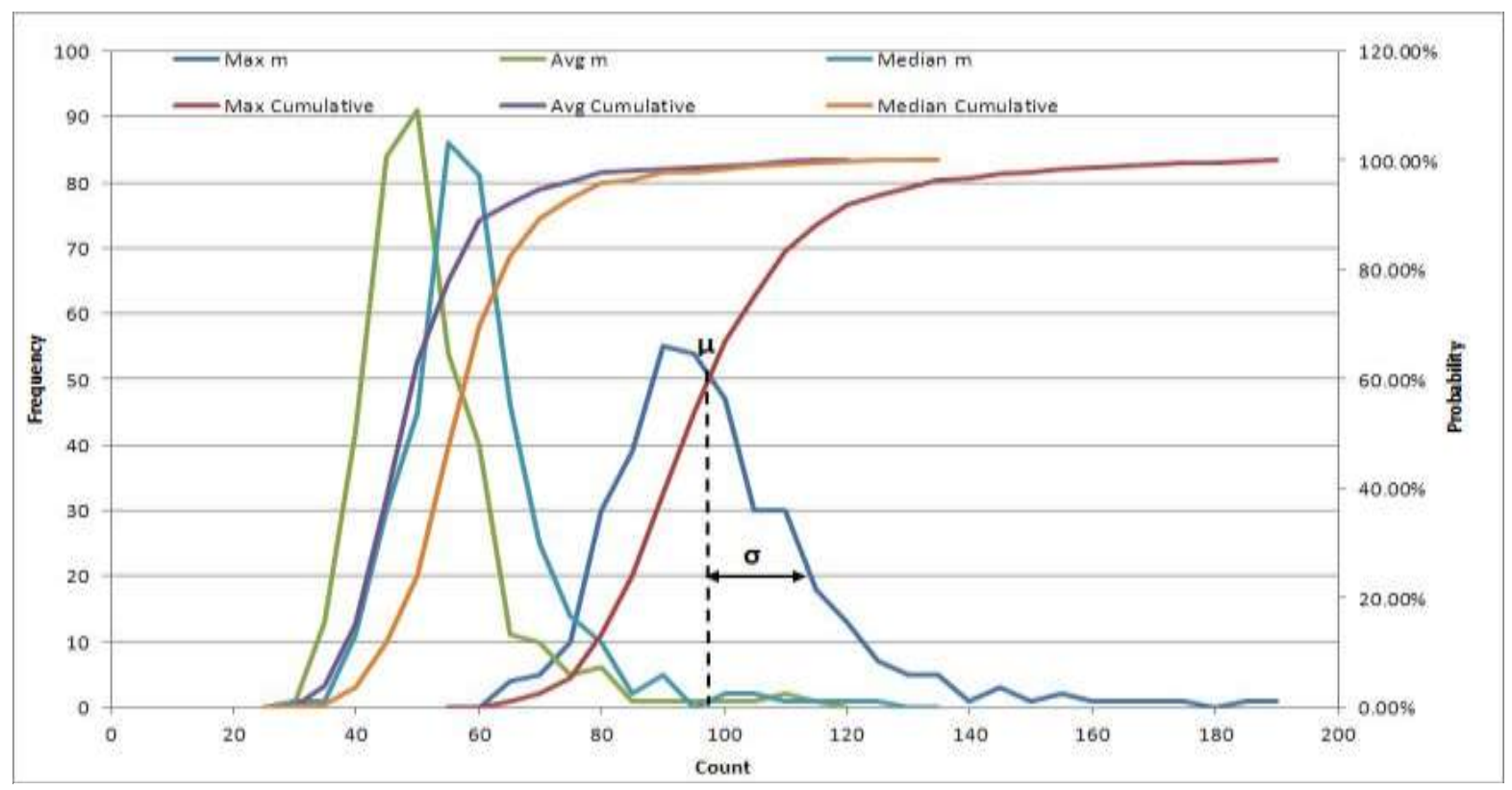

Figure 1 -Density andDistributions for functions of surface count

events when this number has spiked up to more than $134(\mu+2 \sigma)$.

To identify the days with excessive congestion, three thresholds for the value of $\mathrm{M}$ are used: 125 (1.5 $\sigma), 134(2 \sigma)$, and $150(3 \sigma)$. The days for each month that were over the threshold are listed in Table3.

\begin{tabular}{|c|c|c|c|c|c|c|}
\hline ORD & $\begin{array}{c}M>125 \\
(\mu+1.5 \sigma)\end{array}$ & $\begin{array}{l}M>134 \\
(\mu+2 \sigma)\end{array}$ & $\begin{array}{l}M>150 \\
(\mu+3 \sigma)\end{array}$ & Day-M>125 & $\begin{array}{c}\text { Day- } \\
M>134\end{array}$ & $\begin{array}{c}\text { Day- } \\
M>150\end{array}$ \\
\hline Jan & 3 & 2 & 1 & $3,15,21$, & 15,21 , & 21, \\
\hline Feb & 2 & 1 & 0 & 16,25 & 25 & N/A \\
\hline Mar & 1 & 0 & 0 & 23 & N/A & N/A \\
\hline Apr & 0 & 0 & 0 & $\mathrm{~N} / \mathrm{A}$ & N/A & N/A \\
\hline May & 2 & 1 & 0 & 16,31 & 16 & N/A \\
\hline Jun & 4 & 3 & 2 & $18,26,27,28$ & $18,26,27$ & 18,27, \\
\hline Jul & 3 & 1 & 1 & $2,10,18$ & 18 & 18 \\
\hline Aug & 3 & 3 & 1 & $6,19,22$ & $6,19,22$ & 19, \\
\hline Sep & 2 & 1 & 1 & 5,16 & 5 , & 5 , \\
\hline Oct & 1 & 1 & 1 & 18 & 18 & 18 \\
\hline Nov & 0 & 0 & 0 & N/A & $\mathrm{N} / \mathrm{A}$ & N/A \\
\hline Dec & 3 & 2 & 1 & $21,23,30$ & 21,23 & 23 \\
\hline Sum & 24 & 15 & 8 & & & \\
\hline
\end{tabular}

Table 3 -Days with excessive congestion

In 2007 there were a total of 8 days during 2007 that had congestion on the surface, with greater than 150 flights on the surface other than those sitting at the gates.
The next section discusses the particular days that congestion occurred and the reasons and consequences of the congested days.

\section{Discussion}

The first case study: January 21, 2007. The value for $\mathrm{M}$ on this day at ORD is 153 . To put the results in perspective, January 28, 2007, a week from that day, is chosen to compare the results. Table 4 provides the summary of operations done on each day. Note that the value of M for Jan-28 is only 103. The initial count of flights on the surface on Jan-21 is 326 and the count for Jan-28 is 354 (See Figure 2).

\begin{tabular}{|c|c|ccc|}
\hline ORD & Days & $\begin{array}{c}\text { Ops. } \\
\text { Count }\end{array}$ & $\begin{array}{c}\text { Delay } \\
\text { Min }\end{array}$ & $\begin{array}{c}\text { Taxi } \\
\text { Min }\end{array}$ \\
\hline \multirow{2}{*}{ Departure } & 21-Jan & 1200 & 83403 & 41939 \\
& 28-Jan & 1512 & 49499 & 31289 \\
\hline \multirow{2}{*}{ Arrival } & 21-Jan & 1199 & 96726 & 32507 \\
& 28-Jan & 1513 & 53440 & 16981 \\
\hline
\end{tabular}

Table 4 -Comparison of operations, 21st vs. 28th

Note that, although these days are same days of the week, the number of performed operations on Jan-21, which is a "bad day", is much less than the "good day', which are about 300 fewer departures as well as 300 less arrivals. This is approximately $20 \%$ less operations compared to the good day but congestion levels are much higher. Figure 2 shows the values for GC, SC and M throughout the day for 


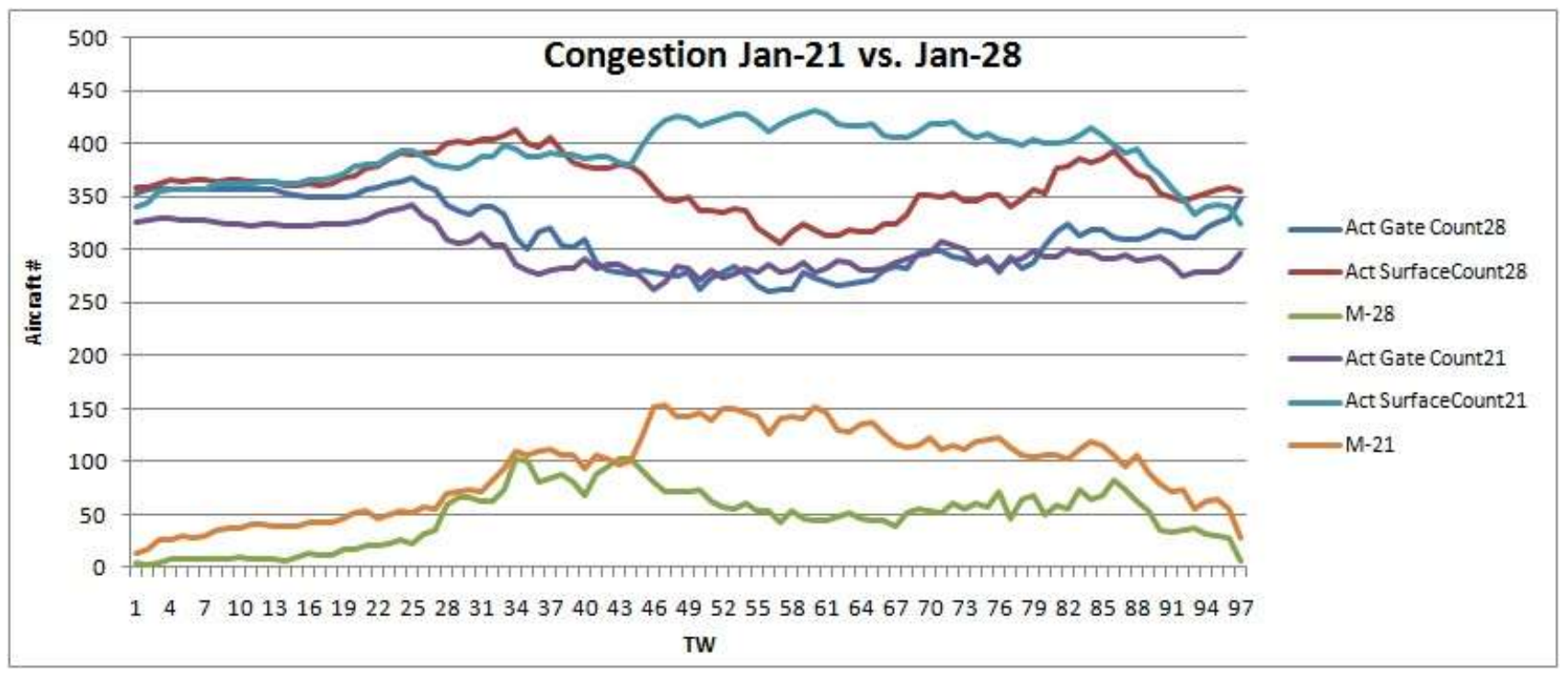

Figure 2 -Comparison of congestion between 21st and 28th

both days. It can be seen that approximately around 11:00 a.m. the value of $M$ for the bad day starts to increase and stays high for hours before it starts to decline.

To explain the reason for such congestion, these days are analyzed in more detail. Looking at the weather conditions in Jan-21-2007 at ORD, on this day, the airport was operating five different configurations, which is an indicator of changing weather conditions at the airport. Table 5 lists the different configurations operated on this day.

\begin{tabular}{|c|c|}
\hline $\mathrm{ID}$ & Configuration \\
\hline 1 & $14 \mathrm{R}, 22 \mathrm{~L}, 22 \mathrm{R} \mid 9 \mathrm{~L}, 22 \mathrm{~L}, 27 \mathrm{~L}$ \\
2 & $9 \mathrm{~L}, 9 \mathrm{R} \mid 4 \mathrm{~L}, 9 \mathrm{R}, 32 \mathrm{R}$ \\
3 & $4 \mathrm{R}, 9 \mathrm{R} \mid 4 \mathrm{~L}, 9 \mathrm{~L}, 32 \mathrm{~L}, 32 \mathrm{R}$ \\
4 & $9 \mathrm{~L}, 9 \mathrm{R} \mid 4 \mathrm{R}, 22 \mathrm{~L}, 32 \mathrm{R}$ \\
5 & $4 \mathrm{R}, 9 \mathrm{~L}, 9 \mathrm{R} \mid 4 \mathrm{~L}, 9 \mathrm{~L}, 32 \mathrm{~L}, 32 \mathrm{R}$ \\
\hline
\end{tabular}

Table 5 -Operated configurations on $21 \mathrm{st}$

Figure 3 shows the changes in configuration and the length of time each configuration was operated. It also presents the Average Arrival Rates (AAR) and Average Departure Rates (ADR) set on that day to be operated.

It can be seen in Figure 3, that there were several configuration changes in the afternoon. Also after noon, ADR was set to be little higher than AAR. It can be seen that AARs and ADRs are changing throughout the day, which suggests the changing weather condition as well as the need to adjust the operations to satisfy the demand for departure and arrival

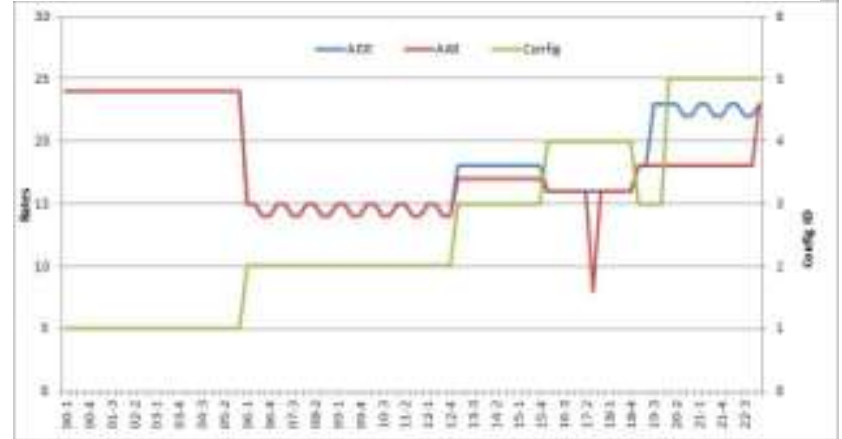

Figure 3 -Planned operations rate and operated config. ,21st

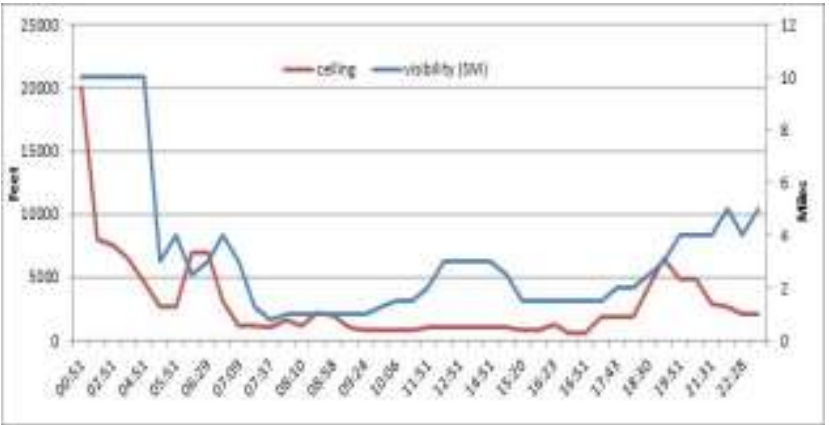

Figure 4 -Ceiling and visibility, $21^{\text {st }}$

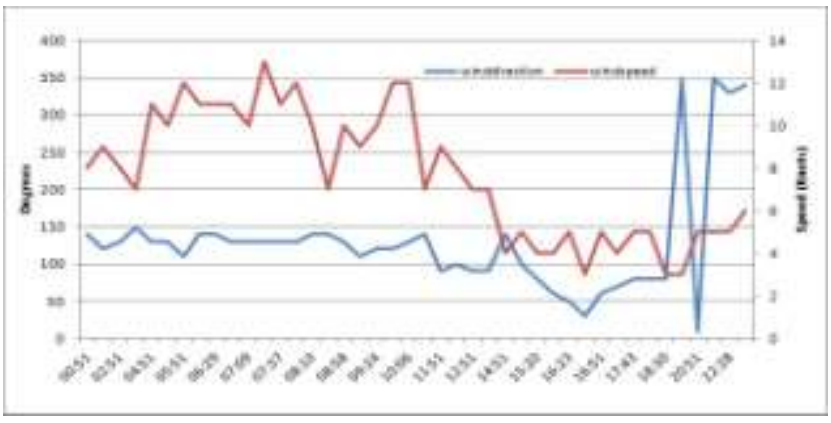

Figure 5 -Wind conditions, 21st 


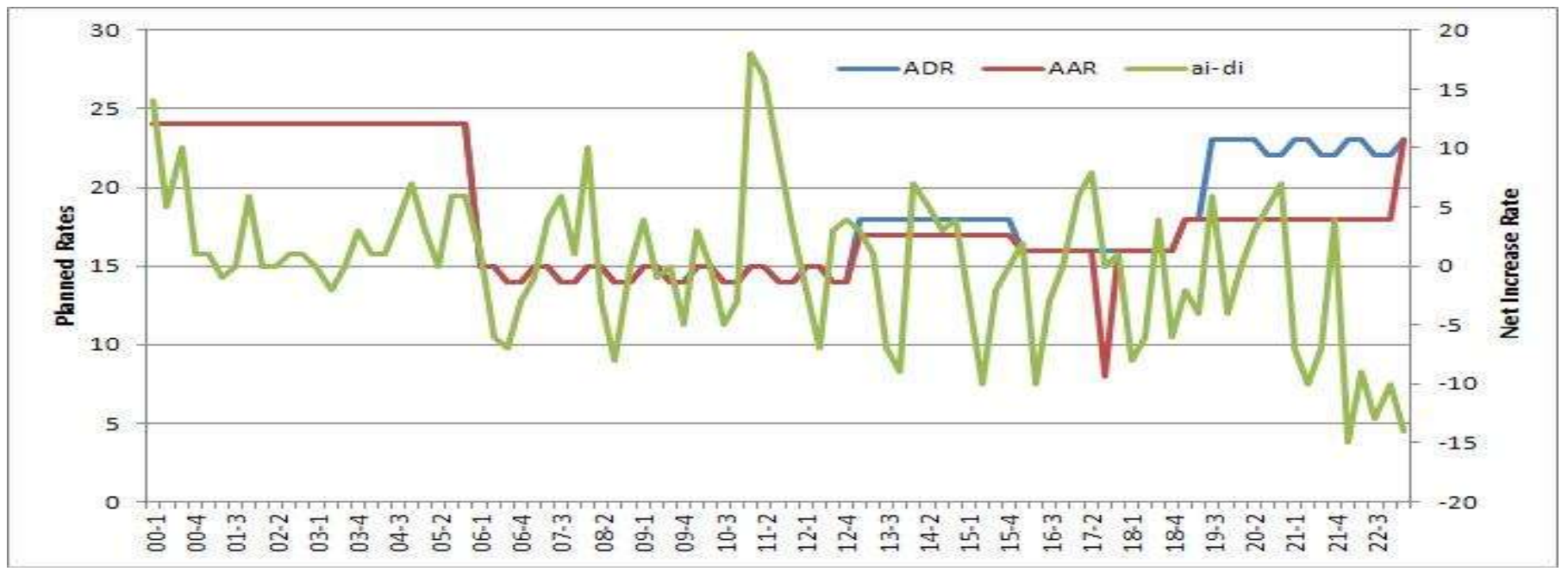

Figure 6 -Planned vs. actual operations

Visibility dropped below 1 mile between 8 am and $5 \mathrm{pm}$, with ceiling as low as $600 \mathrm{ft}$ during this period. Wind direction and magnitude fluctuated during the day. In particular, the wind direction shifted from 150 degrees to 50 degrees around $2 \mathrm{pm}$ local time (Figure 5). Figure 4 and 5; present the weather conditions on Jan-21 at ORD.

In contrast, the good day (Jan $28^{\text {th }}$ ), also experienced relatively low ceiling before noon and after 2:00 pm. Visibility was low in the beginning of the day dropping down to 0.75 miles but at 11:00 am, visibility increases to 10 miles. The airport was operating three configurations that are very similar to each other (adding one runway) and there have been six changes between mentioned operating configurations throughout the day.

To see how the actual operations differed from planned operations at the airport, Figure 6, captures the actual number of operations (landings minus takeoffs) at each time interval during the day. It is important to note that the surface count, and therefore the surface congestion, is in direct relation with operations. Departures will generally decrease the SC while arrivals will increase the surface count.

It should be kept in mind that permission to push back from the gate into an "already congested" surface does not relieve the situation. The reason is, movements in a congested surface is limited and not smooth, therefore pushing back from the gates will add to the flights on the surface which can actually cause more delay due to grid-lock on taxi ways.

It can be seen that around the time (noon), when the number of flights on the surface but not at the gates $\left(\mathrm{m}_{\mathrm{t}}\right)$ spikes, is the time that the actual take-offs are decreased and there has been a spike in the number of landings into the airport. Operating in such conditions even for just 3 time windows adds 42 airplanes to the surface of the airport. In Figure 6, actual net operations are compared to those set by the Traffic Manager.

Figure 8 , uses the net rate of change in surface count which takes gate operations into account and compares January $21^{\text {st }}$ and $28^{\text {th }}$. Since congestion on the surface is a direct consequence of managing runways and gates. Both runways and gates can feed

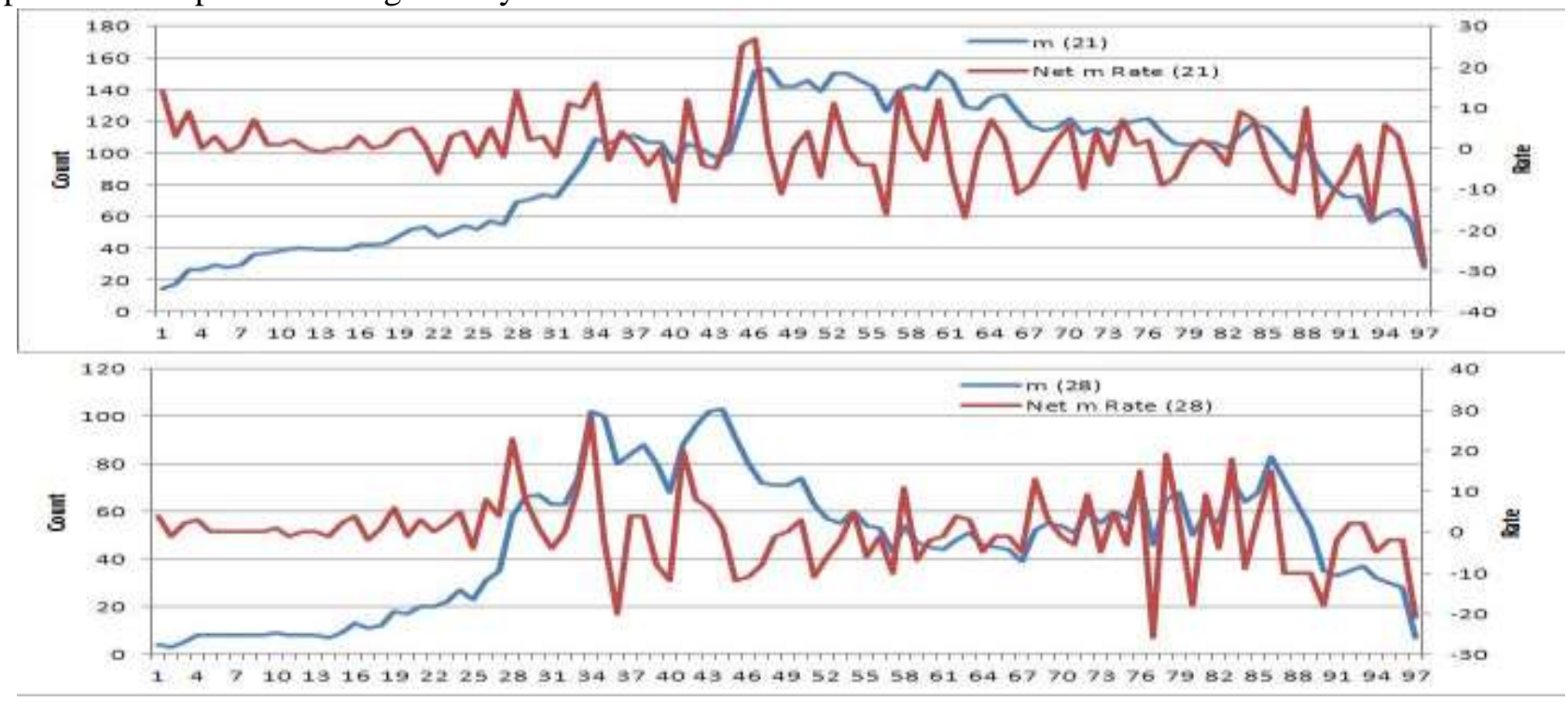

Figure 7 -Congestion and congestion rate, 21st vs. 28th 


\begin{tabular}{|c|c|c|c|c|c|c|c|c|c|c|c|c|}
\hline \multirow{2}{*}{$\begin{array}{l}\text { ORD- } \\
2007\end{array}$} & \multicolumn{3}{|c|}{ Airport Departure Rate } & \multicolumn{3}{|c|}{ Departure Demand } & \multicolumn{3}{|c|}{ Airport Acceptance Rate } & \multicolumn{3}{|c|}{ Arrival Demand } \\
\hline & Average & Sum & Max & Average & Sum & Max & Average & Sum & Max & Average & Sum & Max \\
\hline 21-Jan & 19.1 & 1832 & 24 & 22.1 & 2124 & 48 & 18.2 & 1748 & 24 & 28.6 & 2744 & 67 \\
\hline 18-Jun & 20.7 & 1990 & 25 & 23.4 & 2250 & 77 & 19.6 & 1884 & 25 & 41.6 & 3993 & 120 \\
\hline 27-Jun & 22.3 & 2144 & 24 & 22.5 & 2158 & 60 & 20.4 & 1961 & 24 & 35.8 & 3437 & 105 \\
\hline 18-Jul & 20.8 & 2000 & 24 & 20.3 & 1952 & 46 & 20.8 & 2000 & 24 & 19.7 & 1894 & 48 \\
\hline 19-Aug & 19.9 & 1907 & 25 & 25.9 & 2487 & 94 & 19.7 & 1888 & 25 & 47.4 & 4553 & 101 \\
\hline 5-Sep & 22.8 & 2186 & 24 & 21.5 & 2066 & 71 & 22.8 & 2186 & 24 & 16.7 & 1599 & 46 \\
\hline $18-O c t$ & 19.3 & 1851 & 22 & 24.9 & 2395 & 83 & 18.7 & 1797 & 22 & 47.9 & 4601 & 117 \\
\hline 23-Dec & 16.1 & 1543 & 18 & 19.5 & 1874 & 49 & 15.8 & 1515 & 18 & 41.2 & 3954 & 102 \\
\hline
\end{tabular}

Table 6 -summary of operations, $3 \sigma$ days

into/from the surface.

It can be seen that although, the general trend is following the planned operations, extreme volatilities and variations around the planned values will cause variations in count of flights on the surface. In normal circumstances, if there is not serious congestion on the surface, these volatilities in following the planned operations might not cause any interruptions in the operations. On the other hand, existing volatilities and extreme deviations from planned surface operations while under heavy surface congestion, can push the airport beyond its operating capabilities, causing additional delays.

Note that Surface capacity of an airport is specific to the airport, configuration of the terminals and, operating runways. It is the number of flights that can be present on the surface while all the surface operations can be carried out smoothly without interrupting or blocking other operations. This number can be provided by experts.

In case of individual airports operations, imbalances in Airport Departure Rate (ADR) and Airport Acceptance Rate (AAR) can lead to a congested surface. Construction, weather, deicing operations etc. can be other factors leading to an over-populated surface.

It is expected that during surface congestion times, taxi times also increase. In other words, a congested surface would interrupt smooth operation on the surface of the airport, which in turn, can prolong taxi times. To test this hypothesis, the correlation between total taxi times and maximum surface congestion throughout the year was calculated. Total Taxi-Out time for departures correlates with maximum surface flight count 0.73 using a Microsoft Excel Data Analysis Correlation Test. This shows strong correlation between surface congestion and total taxi out times. This means that increasing congestion is likely to increase taxi out times. Taxi-In time for arrivals correlates with maximum surface flight count 0.396 using the same test. This does not show very strong correlation which means that surface congestion does not increase taxi-in times as much as taxi-out times. This can be another indicator of how arrivals are preferred over departures.

Table 6 represents the summary of operations and demand information for all the $\mu+3 \sigma$ days. To better show the dynamics of the operations and demands, the average values, total sums and maximum values are calculated. The values for rates are for each 15-minute time window of the day. The maximum, average, and sums are calculated using the every 15-minute interval data point values. For example, the maximum arrival demand is the maximum value of arrival demand over a 15-minute time interval.

It is important to note, in all days there has been

\begin{tabular}{|c|ccc|cc|cc|c|}
\hline \multirow{2}{*}{$\begin{array}{c}\text { ORD- } \\
\text { 2007 }\end{array}$} & \multicolumn{3}{|c|}{ Ceiling } & \multicolumn{2}{|c|}{ Wind Speed } & \multicolumn{2}{|c|}{ Visibility } & \multirow{2}{*}{$\begin{array}{l}\text { \#Co } \\
\text { nfig. }\end{array}$} \\
\cline { 2 - 8 } 21.. & Avg. & Min & Avg. & Max & Avg. & Min & \\
\hline 21-Jan & 0 & 3963.5 & 600 & 7 & 13 & 5 & 1 & 6 \\
18-Jun & 40.6 & 8001 & 2200 & 12.1 & 22 & 8.2 & 3 & 6 \\
27-Jun & 28.1 & 10833 & 3500 & 7.8 & 18 & 8.9 & 3 & 3 \\
18-Jul & 12.5 & 6377 & 2600 & 10.2 & 23 & 9.4 & 0.8 & 7 \\
19-Aug & 0 & 2765.6 & 400 & 7.8 & 15 & 5.8 & 1.5 & 3 \\
5-Sep & 79.1 & 2781.3 & 10000 & 6.9 & 26 & 8.4 & 6 & 5 \\
18-Oct & 37.5 & 2963.5 & 1300 & 18.7 & 28 & 9.3 & 3 & 3 \\
23-Dec & 0 & 2044.8 & 900 & 24.9 & 34 & 4.2 & 0.5 & 3 \\
\hline
\end{tabular}

Table 7 -Summary of weather conditions, $3 \sigma$ days

excessive demand for runway operations while the available capacity has not been enough to accommodate the existing demand. In all of the cases but the case of September $5^{\text {th }}$, the maximum demand for arrival is much greater than the maximum value of departure demand. Excessive arrival demands might create an urgent priority of arrivals over departures that can push the count of flights on the surface beyond the carrying limits. 
Table 7, shows the weather information on all the bad days that airport congestion existed. First column shows the percentage of the time that there has not been any ceiling. Average wind speed is showing how bad the winds were during the day while the maximum speed shows the worst conditions.

Same line of reasoning goes for the visibility. On the last column total number of configurations operated (not necessarily distinct) throughout the day.

\section{Conclusion}

This paper describes a methodology for systematic analysis of surface grid-lock using publicly available data. A case study for ORD in 2007 is presented. Importance

Traditional thinking about Air Traffic Flow Management (ATFM) tends to be limit to thinking of the network and runways as the only capacitated elements at the airports.

This research shows that it is feasible to have consecutive time intervals of imbalanced operations. In this way, the imbalanced arrival/departure operations can push the airport into a grid-lock (excessive congestion) and consequently more delay.

The importance and fundamental differences of gate departures/ arrivals versus runway departure/ arrivals are also highlighted.

In the latter case, contributing factors might exist due to imbalances in the air transportation network, not solely related to the airport of study. For example, weather conditions can force MDW to use ILS approach 13C, while the interacting airport ORD cannot have departures out of $22 \mathrm{~L}$, due to the shared airspace between MDW and ORD which is known as metroplex effects. This usually happens because arrival flights are usually given higher priorities over departure flights [10]. This can lead to congestion on the surface at ORD.

Similarly, flights departing from LGA to south, are given priority over flights departing from PHL using the same (constrained) airspace, which can cause surface congestion at PHL [10].

\section{References}

[1] Zhang, Wei, M. Kamgarpour, D. Sun, Claire J. Tomlin, 2011, A Hierarchical Flight Planning Framework for Air Traffic Management, Proceedings of IEEE.

[2] Ball, Micheal, C. Barnhart, M. Dresner, M. Hansen, K. Neels, A. Odoni, E. Peterson, L. Sherry, A. Trani, B. Zou, 2010, Total delay impact study a comprehensive assessment of the costs and impacts of flight delay in the United States, Univ. California Berkeley, Berkeley, CA, Nat. Cntr. Excellence Aviations Oper. Res.

[3] www.transstat.bts.gov

[4] Gilbo, Eugene P., 1993, “Airport Capacity: Representation, Estimation, Optimization", Vol. 1, NO. 3, IEEE Trans. Ctrl Syst. Tech.

[5] Bersimas, Dimitris, G. Lulli, A. Odoni, 2011, “An Integer Optimization Approach to Large-Scale Air Traffic Flow Management", Vol. 59, No. 1, Operations Research.

[6] Bertsimas, Dimitris, M. Frankovich, A. Odoni, 2011, "Optimal Selection of Airport Runway Configuration", Vol. 59, No. 6, Operations Research.

[7] Stell, Laurel L., 2006, Airport Gridlock Research Report, Metron Aviation.

[8] Stroiney, Steven, B. Levy, May 2011, Departure Queue Management Benefits Across Many Airports, Integrated Communications Navigation and Surveillance (ICNS)

[9] Simaiakis, Ioannis, H. Balakrishnan, 2011, Departure Throughput Study for Boston Logan International Airport, MIT, ICAT.

[10] Jehlen, Richard, 2012, "Best Equipped-Best Served (BEBS)", Federal Aviation Administration.

\section{Acknowledgements}

This research was partially funded by Crown Consulting Inc. and internal GMU Research Foundation funds. Thank you for technical assistance: George Donohue, John Shortle, Jie Xu, Akshay Belle, Yimin Zhang, Kevin Lai, Zhenming Wang, Houda Kourdali (Center for Air Transportation Systems Research at George Mason University), Michael Wambsganns, Anastasia Mukhina, Liviu Nedelescu, Matt Blake (Crown 
Consulting), Paula Lewis, Richard Jehlen, Dan Murphy (FAA), Ben Levy (Saab-Sensis).

\section{Email Addresses}

sneyshab@gmu.edu

1sherry@gmu.edu khoffman@gmu.edu

2013 Integrated Communications Navigation and Surveillance (ICNS) Conference April 23-25, 2013 